\title{
TIRANDO O ENSINO JURÍDICO DO “ARMÁRIO”: POSIÇÕES DE ESTUDANTES DO CURSO DE DIREITO SOBRE DIVERSIDADE SEXUAL E DE GÊNERO NO CURRÍCULO UNIVERSITÁRIO
}

\author{
TAKING LEGAL EDUCATION OUT OF THE "CLOSET": IMPRESSIONS OF LAW \\ STUDENTS ABOUT SEXUAL AND GENDER DIVERSITY IN THE ACADEMIC \\ CURRICULUM
}

\author{
Túlio Vinícius Andrade Souza ${ }^{1}$ e Maria Cristina Lopes de Almeida Amazonas² \\ ${ }_{1}$ Universidade Federal de Pernambuco, Departamento de Pós-Graduação em Psicologia, Brasil, e- \\ mail: tulio.andrade09@gmail.com, ORCID: https://orcid.org/0000-0002-9897-8327 \\ 2 Universidade Católica de Pernambuco, Docente do Departamento de Psicologia, Brasil, e-mail: \\ crisamaz@gmail.com, ORCID: https://orcid.org/0000-0002-0503-1477
}

A R T I C L E I N F O
Article history:
Received 2020-05-28
Accepted 2020-11-30
Available online 2020-11-30

RESUMO. A escassa literatura sobre ensino jurídico e diversidade sexual e de gênero indica que as faculdades seguem um padrão tradicional e tecnicista, não dialogando com questões sociais, necessárias para profissionais do Direito. Diante disso, o presente trabalho buscou investigar se futuros profissionais se sentem preparados para lidar com questões relacionadas à diversidade sexual e de gênero e quais relações eles estabelecem entre suas formações universitárias e seus graus de preparo/competência. Foi realizada, então, uma pesquisa empírica de cunho exploratório, através da aplicação de 200 questionários com estudantes do último ano da graduação em Direito de uma universidade particular de Recife. Os dados coletados foram tabulados e analisados através de uma abordagem quantitativa, demonstrando, sobretudo, que apesar de uma parcela significativa (40\%) dos pesquisados se sentir preparada para trabalhar com demandas de diversidade de gênero e sexualidade na sua prática profissional, poucos deles atribuem essa preparação ao ensino universitário, ou seja, $76,5 \%$ apontam que a universidade não ofereceu (13,5\%) ou ofereceu pouca (63\%) formação em diversidade sexual e de gênero. Com isso, então, pode-se dizer que o pensamento jurídico brasileiro carrega raízes do modelo positivista e, por isso, se limita, muitas vezes, ao que está posto nas leis e códigos. É necessário repensar o modelo de ensino jurídico vigente, suas características e a atuação docente perante o mesmo e, assim, potencializar o Direito enquanto ciência que desempenhe um papel importante no combate à discriminação, ao preconceito, produzindo mecanismos que garantam, efetivamente, direitos fundamentais a populações vulneráveis.

ABSTRACT. The scarce literature on legal education and sexual and gender diversity indicates that
universities follow a traditional and technical pattern, without dialogue on social issues necessary for legal
professionals. Therefore, the present study aimed to investigate whether future professionals feel prepared to
deal with issues related to sexual and gender diversity and what relationships they establish between
university degrees and degrees of preparation/competence. For this purpose, an empirical research was
carried out with the application of 200 questionnaires, with undergraduate law students from a private
university in Recife. The data collected were tabulated and analyzed using a quantitative approach,
demonstrating, mainly, that despite a significant portion (40\%) of the researchers feel prepared to work with
demands on gender and sexuality diversity in their professional practice, only a few of this preparation is 
attributed to the university, that is, $76.5 \%$ points to a university that does not offer $(13.5 \%)$ or offers little $(63 \%)$ training in sexual and gender diversity. With that, then, it can be said that Brazilian legal thought carries the roots of the positivist model and, therefore, is often limited to what is laid down in laws and codes. It is necessary to rethink the current legal education model, its resources and the observed teaching performance and, therefore, potentialize law as a science that plays an important role in combating discrimination, prejudice, producing of instruments that effectively guarantee vulnerable population.

\section{Introdução}

Durante a construção da ideia deste trabalho, tínhamos em mente o desejo de problematizar a formação universitária em Direito e correlacionar com a temática de diversidade sexual e de gênero, objetivando entender se os futuros profissionais do âmbito jurídico estariam preparados para trabalhar com tais questões. Tal escolha justifica-se através da precária literatura, que mostra que uma das dificuldades enfrentadas na implantação do ensino jurídico no Brasil foi obter um corpo docente habilitado para desenvolver as disciplinas que compuseram a matriz curricular da época. Isso porque, historicamente, os professores que faziam parte dos quadros das instituições de ensino jurídico eram advogados, juízes entre outros profissionais atuantes nas várias áreas forenses (FRANCISCHETTO, 2012). Outros indicam, por sua vez, a rigidez de um currículo que não dava espaço para debates de temas sociais e da realidade, ou seja, algo que tivesse fora das leis e códigos.

Nesse sentido, então, as aulas de Direito, dentro do padrão tradicional e tecnicista, parecem desenvolver-se, até hoje, numa realidade paralela, onde o que se estuda parece estar estático há décadas, ignorando-se que a realidade social é dinâmica, dentre elas, as questões que envolvem direitos humanos.

Quando se trata de preservar os direitos humanos, é importante pensar nos direitos sexuais. A sexualidade é parte integrante das relações sociais, interferindo e moldando a vida pública dos indivíduos e garantindo (ou não) o acesso aos direitos. Assim, os direitos sexuais devem ser considerados como inalienáveis e indispensáveis na construção de uma sociedade mais justa e igualitária (MISKOLCI, 2010). Para a Organização Mundial de Saúde (OMS), os direitos sexuais incluem todas as pessoas e repudiam qualquer forma de coerção, discriminação ou violência, devendo ser protegidos e respeitados.

Apesar desse compromisso assumido pela OMS, os direitos da população LGBTQI+ (lésbicas, gays, bissexuais, transexuais e transgêneros, queer, intersexuais e outras denominações) ainda não são devidamente reconhecidos e respeitados e casos de 
discriminação LGBTQlfóbicas são frequentes em diversas partes do mundo (BRAVO \& PLATERO, 2002).

Por outro lado, no que se refere à formação de profissionais em Direito, Dias (2014) afirma que sempre foi severa a resistência dos advogados em atender ao segmento homossexual. Com a desculpa de não existir lei, sempre desestimularam os clientes a buscarem a tutela jurídica. No entanto, no início deste século, em face de algumas decisões que se notabilizaram pelo vanguardismo, teve início a construção do Direito Homoafetivo como um novo ramo do Direito. A partir do momento em que foi criada a Comissão Especial da Diversidade Sexual do Conselho Federal da Ordem dos Advogados do Brasil, houve um aumento expressivo de ações em juízo. Todavia, parece que a lacuna está presente na formação universitária de futuros profissionais do campo jurídico, considerando as recentes (e demoradas) mudanças no âmbito do Direito Homoafetivo.

Tendo elegido o nosso campo de análises, e percebendo as lacunas dos poucos estudos teóricos sobre gêneros e sexualidades no ensino jurídico, optamos por realizar uma pesquisa empírica de cunho exploratório, a fim de compreender as percepções das(os) estudantes do curso de Bacharelado em Direito de uma universidade privada, localizada em Recife - PE, sobre tais problemáticas.

Assim, considerando que um jurista, hoje, está cada vez mais inserido nos serviços e nas políticas públicas que envolvem a população LGBTQI+, neste artigo, pretende-se analisar como está ocorrendo à formação desses profissionais para lidar com questões que envolvam gêneros e sexualidades, investigando se futuros profissionais do âmbito jurídico (último ano da graduação em Direito) se sentem preparados para lidar com essas questões e verificando as relações que eles estabelecem entre suas formações universitárias e seus graus de preparo/competência. Este estudo pode contribuir para a proposição de ações voltadas à formação do profissional de Direito que incorporem uma perspectiva política voltada à proteção aos direitos da comunidade LGBTQI+ e ao acolhimento responsável de gêneros e sexualidades dissidentes.

Esse artigo, então, resulta de uma pesquisa empírica realizada no âmbito do Programa Institucional de Bolsas de Iniciação Científica (PIBIC) da Universidade Católica de Pernambuco (UNICAP), e orientada pela professora Doutora Maria Cristina Lopes de Almeida Amazonas, coautora e docente da graduação e pós-graduação em Psicologia da UNICAP. Os dados aqui discutidos foram apresentados no Simpósio Temático (ST 12): "Gêneros e sexualidades dentrofora dos cotidianos escolares: disputas, atravessamentos e práticas", durante o IV Seminário Internacional Desfazendo Gênero, que aconteceu entre 13 
e 15 de novembro de 2019, em Recife, Pernambuco, resultando no convite da revista REVES (Revista Relações Sociais) para publicação do manuscrito.

\section{Metodologia}

A presente pesquisa consiste em um levantamento de campo que, de acordo com Gil (2008), caracteriza-se pela interrogação direta das pessoas cujo comportamento se deseja conhecer. Selltiz (1967) pontua que, em pesquisas que têm como objetivo familiarizar-se com o fenômeno ou conseguir nova compreensão do mesmo, estudos do tipo exploratório são os mais indicados. Dessa forma, então, consiste em uma pesquisa aplicada, com delineamento de estudo exploratório, que conduz a um conhecimento mais profundo a respeito do grupo de indivíduos que está sendo analisado.

Nesse estudo, para atingir os objetivos previamente estabelecidos, foi construído um questionário composto por 20 questões mistas, ou seja, segundo Gil (2008), questões abertas (solicita-se aos respondentes que ofereçam suas próprias respostas), fechadas (pede-se aos respondentes para que escolham uma alternativa dentre as que são apresentadas numa lista) e uma questão dependente (quando ela só faz sentido se uma alternativa anterior for escolhida), tendo como ponto de partida o que foi previamente estabelecido entre os objetivos.

Dessa maneira, envolve a coleta de dados de natureza primária, que foram analisados através de uma abordagem quantitativa. Segundo Fachin (2003), a abordagem quantitativa é realizada por meio de uma proporção de números. Esta quantificação envolve um sistema lógico que sustenta a atribuição de números com resultados eficazes. Os dados coletados foram tabulados e, quando possível, apresentados em gráficos para facilitar a análise.

O universo da pesquisa são estudantes do último ano ( $9^{\circ}$ e $10^{\circ}$ semestres) da graduação do curso superior de Bacharelado em Direito de uma universidade particular, localizada em Recife/PE. E, assim, esse foi o único critério para seleção da amostra, sem maiores restrições, objetivando uma heterogeneidade entre os pesquisados.

Para determinar o tamanho de uma amostra estatisticamente válida, aplicamos a "Fórmula para o Cálculo de Amostras para Populações Finitas", que leva em consideração o tamanho da população, ou seja, o número total de pessoas do grupo a ser estudado; a margem de erro, que é uma porcentagem que indica o nível de correspondência dos 
resultados do questionário com as opiniões da população total e, quanto menor a margem de erro, mais próximo o pesquisador está de ter a resposta exata a um grau de confiança específico e, por fim, o escore $z$, que é o número de desvios padrão entre determinada proporção e a média, dependendo do grau de confiança desejado. Assim, o tamanho da população correspondia a 655 estudantes que, com um nível de confiança de $95 \%$ e margem de erro de 5,78\%, implicou o total de 200 questionários aplicados e analisados.

Quanto aos aspectos éticos, o projeto de pesquisa que possibilitou a coleta de dados foi aprovado pelo comitê de ética das entidades competentes (CAAE 61435416.1.0000.5206). Além disso, em se tratando de uma pesquisa com seres humanos que não submete os envolvidos a riscos maiores do que os corriqueiramente oferecidos pela vivência diária, pois que os assuntos abordados no questionário dizem respeito unicamente à formação profissional dos envolvidos e as impressões deles, pode-se classificar a pesquisa como risco mínimo. Buscando um maior compromisso ético com os indivíduos envolvidos, todos assinaram um Termo de Consentimento Livre e Esclarecido (TCLE) concedendo sua participação na pesquisa e confirmando que foram esclarecidos sobre os objetivos pelos responsáveis da pesquisa, que ressaltaram a possibilidade de desistir de responder ao questionário em qualquer fase do processo, sem danos ou prejuízos ao pesquisado.

Após o preenchimento e coleta, os TCLEs foram mantidos separados dos questionários para evitar qualquer possibilidade de identificação dos respondentes e estão em poder dos pesquisadores, tendo caráter confidencial.

\section{Resultados e discussão}

Inicialmente, é válido traçar o perfil dos respondentes. Isso porque, assim, é possível saber qual o recorte que a pesquisa de campo está inserida. Todavia, salutar relembrar, ainda, que essa amostra já faz parte de um "universo recortado", pois ser estudante da graduação em Direito de uma universidade particular já é um marcador que deve ser considerado.

Nesse sentido, parece ficar claro que a amostra corresponde à realidade de um curso elitista, em uma das universidades particulares do Estado, com maioria branca (65\% dos pesquisados), heterossexual (83\% dos respondentes), autodeclarados cisgênero (100\% dos pesquisados) e cristãos (53,5\% dos respondentes). Assim, discutir temas que envolvem diversidade sexual e de gênero, nesse cenário, pode ser um potencial gerador de 
incômodos e inquietações. Um dado importante, também, é que a maioria corresponde ao sexo feminino $(71,5 \%)$.

Os dados quantitativos serão apresentados de forma a elucidar os objetivos específicos previamente estabelecidos. Assim, nos gráficos abaixo, apresentamos os resultados quanto a se os futuros profissionais do âmbito jurídico se sentem preparados para lidar com questões relacionadas à diversidade sexual e de gênero e as relações que eles estabelecem entre suas formações universitárias e seus graus de preparo/competência para lidar com estas questões.

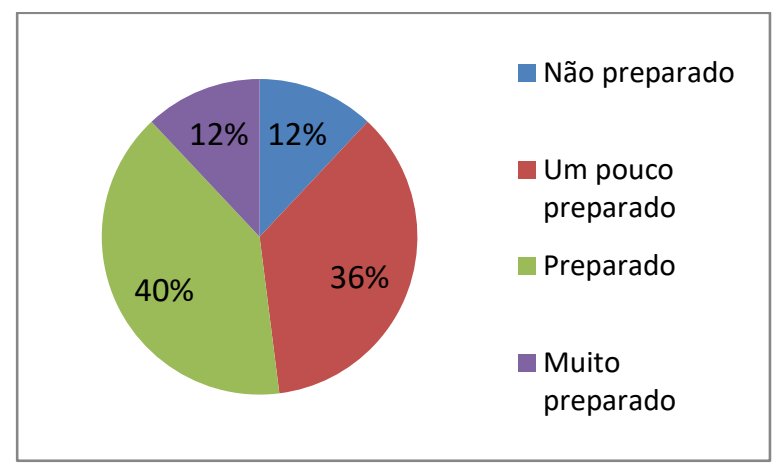

Gráfico 1 - Sentimento de preparação para trabalhar com demandas que envolvam diversidade sexual e de gênero

Fonte: Os autores (2019)

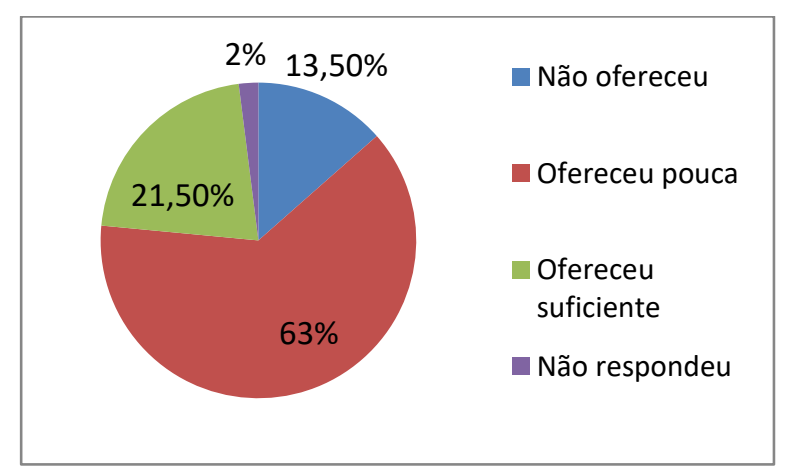

Gráfico 2 - Papel da universidade (se ofereceu formação) em diversidade sexual e de gênero

Fonte: Os autores (2019)

Os gráficos acima demonstram que, apesar de uma parcela significativa $(40 \%=80$ pessoas) dos pesquisados se sentir preparada para trabalhar com demandas de diversidade de gênero e sexualidade na sua prática profissional, poucos deles atribuem essa preparação ao ensino universitário, ou seja, 76,5\% (153 indivíduos) apontam que a universidade não 
ofereceu ( $13,5 \%=27$ estudantes) ou ofereceu pouca $(63 \%=126$ estudantes) formação em diversidade sexual e de gênero.

Além disso, cumpre destacar que $12 \%$ (24 pessoas) "não se sentem preparados" e $36 \%$ (72 voluntários) se sentem "um pouco preparados", enquanto apenas $12 \%$ (24 respondentes) se sentem "muito preparados" para lidar com as referidas questões e, ainda, apenas $21,5 \%$ (43 indivíduos) acredita que a universidade ofereceu formação suficiente, o que denota, se levarmos em consideração a temática, fragilidade do papel da universidade em uma formação social ampla e diversa.

Esses dados escancaram a necessidade urgente de que as universidades, enquanto instituições de ensino e, ainda, os próprios professores, enquanto educadores, reflitam acerca dos mecanismos educacionais que estão sendo utilizados, bem como da prática pedagógica dos docentes e suas implicações na formação de subjetividades que sejam fundamentadas no respeito às diferenças e na defesa da dignidade da pessoa humana. Além disso, é importante pontuar que nenhuma educação é neutra e, conscientes ou não disso, os educadores desenvolvem suas atividades contribuindo, em maior ou menor grau, para a libertação (ou domesticação) dos indivíduos (FREIRE, 2005).

Francischetto (2012) menciona que a crescente demanda que versa sobre as diversidades aqui trabalhadas, ao chegar ao sistema de justiça, encontra profissionais com posturas muito conservadoras e sem abertura para compreender as questões de gênero e de orientação sexual. E, assim, a população LGBTQI+ não é devidamente acolhida pelo Poder Judiciário.

Para a análise acerca da atuação das instituições de ensino é importante, ainda, ter conhecimento se os alunos cursaram disciplinas ligadas ao tema gerador dessa pesquisa (e quais seriam elas). Nesse sentido, então, o gráfico 3 (abaixo) explana o que foi citado.

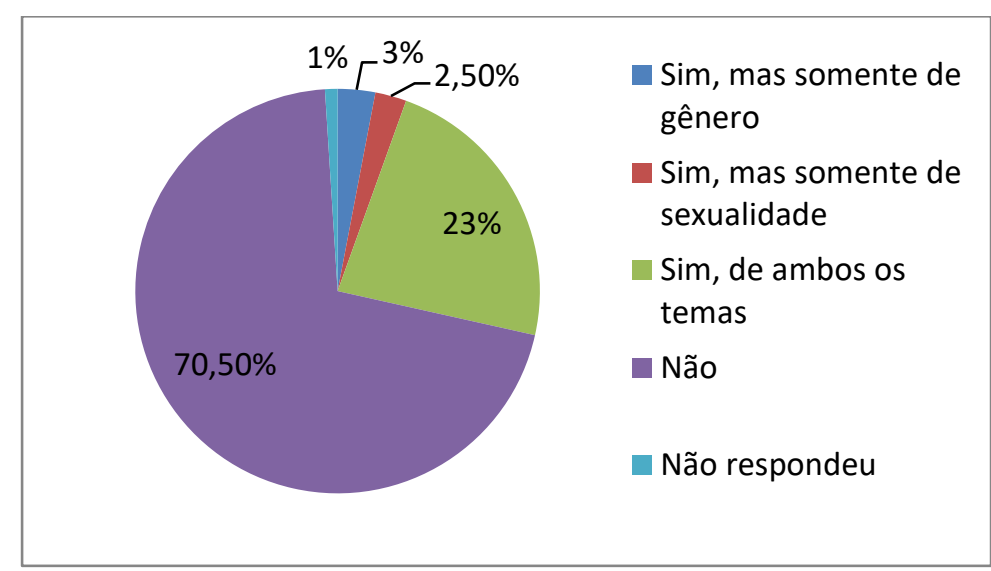

Gráfico 3 - Se os estudantes cursaram alguma disciplina que abordou a temática de gênero ou sexualidade durante a graduação

Fonte: Os autores (2019) 
É possível perceber, assim, que a grande maioria $(70,5 \%$ dos pesquisados $=141$ pessoas) indica que não cursou nenhuma disciplina que abordasse gênero ou sexualidade durante a graduação. Para as pessoas que marcaram a opção "não", existia uma pergunta dependente, questionando o interesse dessas pessoas em cursar (ou não) e, dessa maneira, considerando apenas as pessoas que marcaram a opção mencionada, 105 $(74,47 \%)$ informaram que gostariam de cursar, enquanto 36 (25,53\%) não gostariam.

Com relação aos $23 \%$ (46 pessoas) que marcaram a opção "sim, de ambos os temas", eles apontaram que cursaram as seguintes disciplinas: Direito Civil VI e VII (família e sucessões, respectivamente); Sociologia Jurídica; Direito a Diversidade Inclusão Formal e Material e Biodireito. Das 5 (cinco) disciplinas mencionadas, as 3 (três) primeiras estão no currículo obrigatório e as 2 (duas) últimas compõem o currículo eletivo de disciplinas. Além desses, 3\% (6 respondentes) indicaram que frequentaram disciplinas que tinham uma abordagem "somente de gênero" e 2,5\% (5 pessoas) "somente de sexualidade".

Fomos analisar, então, a "Programação Acadêmica de Disciplina", que contém ementa, conteúdo programático, metodologia e bibliografia, com o objetivo de verificar se, expressamente, existia menção ao tema "gênero" ou "sexualidade" ou se esse trabalho partia de uma iniciativa teórico-metodológica de integrantes do corpo docente. Percebemos, assim, que apenas as disciplinas eletivas (Biodireito e Direito a Diversidade Inclusão Formal e Material) faziam alguma menção.

A disciplina de Biodireito traz, em seu conteúdo programático e metodologia, a seguinte expressão: "direito da personalidade e transexualidade", enquanto Direito a Diversidade Inclusão Formal e Material menciona: "a proteção jurídica à redefinição sexual: o transexual e o acesso à cirurgia de transgenitalização. O direito e a homossexualidade: a natureza da tutela jurídica: individual ou coletiva; casamento; divórcio; alimentos; direito à paternidade e maternidade; adoção de sobrenome; o direito à sexualidade e sua interface com os direitos à liberdade e à dignidade humana; aspectos criminais: a intolerância e o preconceito como condutas tipificadas. $A$ violência e a discriminação na questão do gênero: das condutas reparatórias; a criminalização da violência contra a mulher: antes e depois do advento da Lei Maria da Penha; a condição feminina no direito pátrio; a eficácia dos mecanismos de proteção à mulher brasileira: as garantias da igualdade material; direito à sexualidade e à reprodução.".

É válido observar, no entanto, que da amostra de 200 (duzentos) estudantes, apenas 14 (quatorze) (7\%) cursaram uma das disciplinas eletivas mencionadas. Assim, dos $23 \%$ (46 
pessoas) que marcaram a opção "sim, de ambos os temas", 32 (16\%) alunos consideraram que houve abordagem sobre "gênero" e "sexualidade" nas disciplinas obrigatórias mencionadas.

Tecnicamente abalizando, então, se pensarmos na instituição universidade enquanto tripé ensino-pesquisa-extensão, fica claro a carência e necessidade de avanços no campo pesquisado.

Esses comportamentos poderiam ser ligados, de acordo com Blumenfeld (1992), ao que ele define como "homofobia institucional", ou seja, práticas discriminatórias (com base na identidade de gênero ou orientação sexual) praticadas por empresas, governos, organizações educacionais, religiosas e profissionais. Não se configura apenas através de uma ação, também se manifesta na omissão das mencionadas instituições, seja quando não investigam crimes contra LGBTQI+, não abordam as temáticas transversais com seus funcionários/usuários, na recusa e mau atendimento das vítimas nas delegacias, na omissão do legislativo em aprovar leis, no veto do poder executivo a ações afirmativas que promovam a cidadania LGBTQI+, dentre outras.

Salo de Carvalho (2017) aponta que o estudo da violência homofóbica compreende três níveis de investigação (que não estão em uma hierarquia), esclarecendo:

Primeiro, a violência homofóbica interpessoal, que implica o estudo da vulnerabilidade das masculinidades não hegemônicas e das feminilidades à violência física (violência contra a pessoa e violência sexual); segundo, a violência homofóbica institucional, que se traduz, por um lado, na construção, interpretação e aplicação sexista (misógina e homofóbica) da lei penal em situações que invariavelmente reproduzem e potencializam as violências interpessoais (revitimização), e, por outro lado, na construção de práticas sexistas violentas nas e através das agências punitivas (violência policial, carcerária e manicomial); terceiro, a violência homofóbica simbólica, que compreende os processos formais e informais de elaboração da gramática heteronormativa. (CARVALHO, 2017, p. 239).

Ainda a respeito da homofobia, Borrillo (2009) diz que embora seu primeiro elemento seja a rejeição irracional ou mesmo o ódio em relação a gays e lésbicas, a homofobia não pode ser reduzida a isso. Assim como a xenofobia, o racismo ou o antissemitismo, ela é uma manifestação arbitrária que consiste em designar o outro como contrário, inferior, anormal. Devido a sua diferença, esse outro é posto fora do universo comum dos humanos.

Dessa maneira, uma cultura LGBTQlfóbica tem sido responsável por altos índices de suicídio e de sofrimento psíquico entre essa população e tal sofrimento pode ser consequência da incorporação da visão negativa que a sociedade projeta dos gays, lésbicas, e outras identidades que fogem à norma heterossexual, levando-os a construir uma imagem negativa de si mesmos (SANTOS, COSTA, CARPENEDO \& NARDI, 2011). 


\section{Considerações finais}

Após todo o caminho percorrido para efetuar uma pesquisa empírica, através da aplicação e análise de questionários, acreditamos que, de fato, foi possível traçar como está acontecendo a formação universitária em Direito no que diz respeito às questões relacionadas à diversidade sexual e de gênero, dentro do recorte pesquisado.

É necessário salientar, ainda, que a escassez de referenciais teóricos que discutam o presente tema indica a necessidade de estudos mais aprofundados para se chegar a conclusões mais factuais. No entanto, aqui fazemos considerações sobre os resultados encontrados e materiais teóricos lidos, mesmo com suas limitações.

Percebemos, então, que no cenário brasileiro, o pensamento jurídico carrega raízes do modelo positivista e, por isso, se limita, muitas vezes, ao que está posto nas leis e códigos, apenas. Isso implica, no entanto, a ideia de uma educação jurídica que não contribui, com todo o potencial que possui, para uma formação ampla e humanística dos futuros profissionais.

Nesse contexto, então, é relevante pontuar que nenhuma educação é neutra, ou seja, de alguma forma, influencia os indivíduos. Aplicando tais considerações para o ensino jurídico, é possível inferir que somente por meio da conscientização dos alunos sobre as relações de opressão existentes nas esferas sociais é que seremos capazes de inseri-los em um processo de humanização. Todavia, enquanto o conhecimento dos mecanismos do Direito continuar sendo utilizado como ferramenta para a perpetuação das desigualdades sociais e enquanto os indivíduos que estão intrinsecamente relacionados a ele mantiverem uma suposta neutralidade diante dos dilemas da sociedade atual, estaremos cooperando com a perpetuação das opressões.

Dessa maneira, a colaboração de profissionais do Direito só será efetiva para que a transformação social seja concreta se, de fato, pensarmos um ensino jurídico que valorize os direitos humanos. O caminho, portanto, parece ser mediante uma educação libertadora, comprometida com a conjuntura onde está inserida. Isso porque, uma formação dissociada das questões humanísticas tende a continuar reproduzindo um ensino descontextualizado e acrítico; repercutindo na formação de futuros profissionais que devem estar atentos para a concretização de direitos fundamentais e respeito às diferenças.

No Brasil, os Direitos Humanos ainda precisam ser, realmente, efetivados. Isso pode ser relacionado à insuficiência de esclarecimentos por parte da sociedade, à carência de 
políticas públicas que priorizem esse setor e, ainda, à negligência de muitos profissionais (do Direito, por exemplo) ao abordar a temática. Prova disso, dentre outras razões, é a omissão de debates mais aprofundados sobre Direitos Humanos no contexto universitário.

Nesse ínterim, é crucial considerar que, no ensino jurídico, por existir uma escassez de reflexões sobre problemáticas sociais que envolvem gêneros e sexualidades, consequentemente, também é perceptível a carência de ativismo. Isso porque, um ensino dogmático e descontextualizado implica práticas pedagógicas que não dialogam e afastam os alunos de reflexões necessárias. Esse afastamento entre discentes e as temáticas mencionadas é enorme e demonstra que, além do silêncio universitário, muitos desses estudantes já estão marcados por preconceitos antes mesmo de ingressarem no ensino superior.

Um caminho pode ser a ressignificação da grade curricular das faculdades de Direito, incorporando temas atuais que preocupam a sociedade e, na maioria das vezes, não são considerados para a formação de futuros profissionais do âmbito jurídico.

Fica claro, portanto, a necessidade de reconsiderar o atual modelo do ensino jurídico, suas características teórico-metodológicas e, ainda, a prática pedagógica dos professores. Seria interessante, então, que os docentes vislumbrassem a importância de discutir caminhos para aprimorar o ensino do Direito, de forma que os alunos se sentissem parte do processo de formação de conteúdos, ou seja, alinhando teoria e prática aos diversos contextos.

No entanto, existe a complexidade inerente a qualquer projeto modificador e, por isso, entende-se que todos os que estão envolvidos nesse processo de ensinoaprendizagem devem se responsabilizar pela transformação, ou seja, a iniciativa deve ser conjunta e colaborativa entre administração das instituições de ensino, professores, alunos, pesquisadores, doutrinadores e juristas, em geral.

Fazemos essas considerações, pois visualizamos um grande potencial nas faculdades de Direito enquanto mediadoras com práticas que objetivem a efetivação de direitos da população LGBTQI+. Assim, seria possível desenvolver articulações com movimentos sociais e militância para aproximá-las da universidade, desenvolvendo estratégias de ensino mais interativas. Além de aproximar os movimentos sociais da academia, isso poderia englobar, também, a tríade ensino-pesquisa-extensão, pois é totalmente possível tratar de tais temáticas a partir dessas iniciativas e, assim, potencializar - Direito enquanto ciência que desempenhe um papel importante no combate à discriminação, ao preconceito, produzindo mecanismos que garantam, efetivamente, direitos fundamentais a populações vulneráveis. 


\section{Referências}

BLUMENFELD, W. J. Homophobia: how we all pay the price. Boston, MA: Beacon Press, 1992.

BORRILLO, Daniel. A homofobia. Em Tatiana Lionço \& Débora Diniz. Homofobia \& Educação: um desafio ao silêncio. Brasília: Letras Livres, Ed UnB, 2009.

BRAVO, Rosa Borge \& PLATERO, Raquel Lucas. Diálogos sobre la adopción en España por parejas del mismo sexo: el problema de las prácticas psicológicas discriminatorias. Revista de Teknokultura, 9(2), pp.383-394, 2002.

CARVALHO, Salo de. Criminologia do preconceito: racismo e homofobia nas Ciências Criminais. São Paulo: Saraiva, 2017.

DIAS, Maria Berenice. Homoafetividade e os direitos LGBTI. 6 ed. Reformulada - São Paulo: Editora Revista dos Tribunais, 2014.

FACHIN, O. Fundamentos da Metodologia. 4ª ed. São Paulo: Saraiva, 2003.

FRANCISCHETTO, Gilsilene Passon Picoretti. Ensino Jurídico e Diversidade sexual: Uma formação contra a homofobia institucional. In: II Seminário Nacional de educação, Diversidade sexual e Direitos humanos, 2012, Vitória. Anais do II Seminário Nacional de educação, Diversidade sexual e Direitos humanos, 2012. v. 01.

FREIRE, Paulo. Pedagogia do Oprimido. 42. ${ }^{\mathrm{a}}$ ed. Rio de Janeiro: Paz e Terra, 2005.

GIL, Antônio Carlos. Métodos e Técnicas de Pesquisa Social. 6aㅡ ed. São Paulo: Atlas, 2008.

MISKOLCI, Richard. A sexualidade e o espaço escolar. In: Miskolci, R. (Org.) Marcas da diferença no ensino escolar. São Carlos: EduFSCar, 2010, p. 79-89. 
SANTOS, Camila Backes dos. COSTA, Ângelo Brandelli. CARPENEDO, Manoela. NARDI, Henrique Caetano. A diversidade sexual no ensino de Psicologia. O cinema como ferramenta de intervenção e pesquisa. Sexualidad, Salud y Sociedad. Revista Latinoamericana, n. 7, 127-141, 2011.

SELLTIZ, Claire. Métodos de pesquisa nas relações sociais. São Paulo: Herder, 1967. 